\title{
Dependence of image quality of LGE-MRI of the left atrium on the acceptance rate of respiratory navigator and acquisition time
}

\author{
Sathya Vijayakumar ${ }^{1,2^{*}}$, Chankevin Tek, Nathan S Burgon ${ }^{1}$, Christopher McGann ${ }^{1}$, Nassir F Marrouche', \\ Eugene Kholmovski ${ }^{1,2}$ \\ From 16th Annual SCMR Scientific Sessions \\ San Francisco, CA, USA. 31 January - 3 February 2013
}

\section{Background}

Atrial fibrillation (AF) is a common sustained cardiac arrhythmia associated with increased risks of heart failure and stroke. Late gadolinium enhanced MRI (LGE-MRI) is being routinely used to assess and manage the treatment of AF. To acquire LGE images of thin left atrial (LA) wall high-resolution 3D inversion recovery prepared GRE pulse sequence with cardiac gating and respiratory navigation should be used. This makes the image quality dependent on the patient's heart rate and respiration pattern. In this work, we study the effect of the patient respiration on image quality of LGE-MRI of LA.

\section{Methods}

Images from 70 patients (48 male) aged $66.2 \pm 8.5$ years, who underwent radiofrequency ablation for AF and came back for a 3 or 6-month post ablation MRI follow up, were analyzed. All patients were imaged either on a $3 \mathrm{~T}$ Verio (46) or 1.5T Avanto (24) scanner (Siemens Healthcare, Erlangen, Germany). Dosage of contrast agent (0.1 $\mathrm{mmol} / \mathrm{kg}$, Multihance, Bracco Diagnostic Inc., Princeton, $\mathrm{NJ})$, time after injection (15-25 minutes) and spatial resolution of LGE-MRI $(1.25 \times 1.25 \times 2.5 \mathrm{~mm})$ were the same for both scanners. The other imaging parameters were optimized for respective field strength (1.5T: TR/TE $=5.1 / 2.2$ $\mathrm{ms}$, flip angle $=20$, bandwidth $=290 \mathrm{~Hz} /$ pixel; 3T: TR/TE $=3.1 / 1.4 \mathrm{~ms}$, flip angle $=14$, bandwidth $=750 \mathrm{~Hz} /$ pixel $)$ to achieve high scar visibility. Data for LGE sequence was sampled during LA diastole and data acquisition window was limited to $15 \%$ of cardiac cycle making acquisition time independent on patient heart rate. Two independent

${ }^{1}$ CARMA Center, Dept. of Cardiology, University of Utah, Salt Lake City, UT, USA

Full list of author information is available at the end of the article reviewers graded the images for clarity and visibility of post ablation scar, on a scale of 1-3 as poor, fair, good respectively (Fig 1 ). The acquisition times and the respiratory acceptance rate of the images were recorded and correlated with the average image quality (of the 2 independent readers).

\section{Results}

Figure 2 shows the mean and standard deviation for the acquisition time and respiratory navigator acceptance rate for each of the mean values of image quality. It is clearly seen that the image quality is affected by the acquisition time. Acquisition time for good quality images was less than 8 minutes $(7.8 \pm 1.9)$ while acquisition time for the poorest images was over 14 minutes $(14.7 \pm 4.0)$. The respiratory navigator acceptance rate for good quality images was $47.0 \pm 8.9 \%$, while the poorest images were acquired with an acceptance rate of $27.7 \pm 6.6 \%$. One-way ANOVA performed for the 3 groups of poor, fair, good showed that the differences in acquisition time and acceptance rate are statistically significant $(\mathrm{p}=0.0003$ and $\mathrm{p}=0.0015$ respectively).

\section{Conclusions}

This study shows that the quality of LGE-MRI images is highly dependent on the acquisition time and respiratory navigator acceptance rate. The difference in image quality due to the acquisition time and navigator acceptance rate is statistically significant.

\section{Funding}

This work was funded in part by the Ben B and Iris M Margolis foundation. 


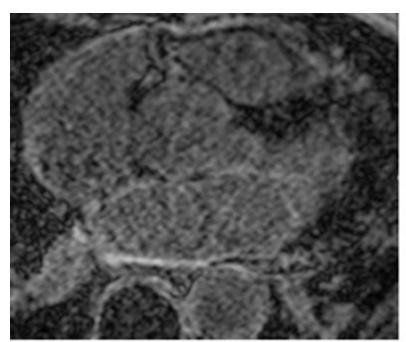

Poor

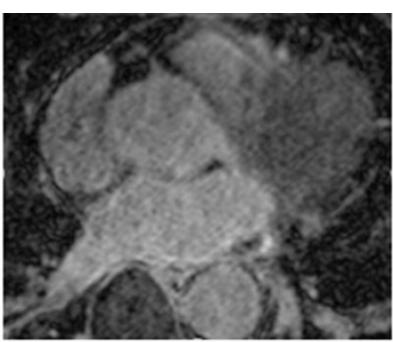

Fair

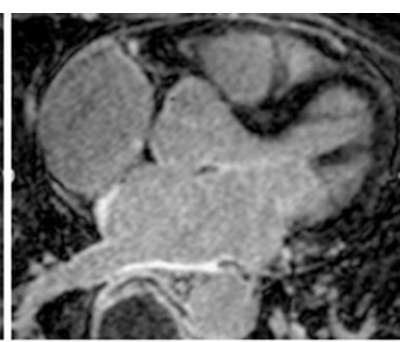

Good

Figure 1 Characteristic images of poor, fair and good quality.

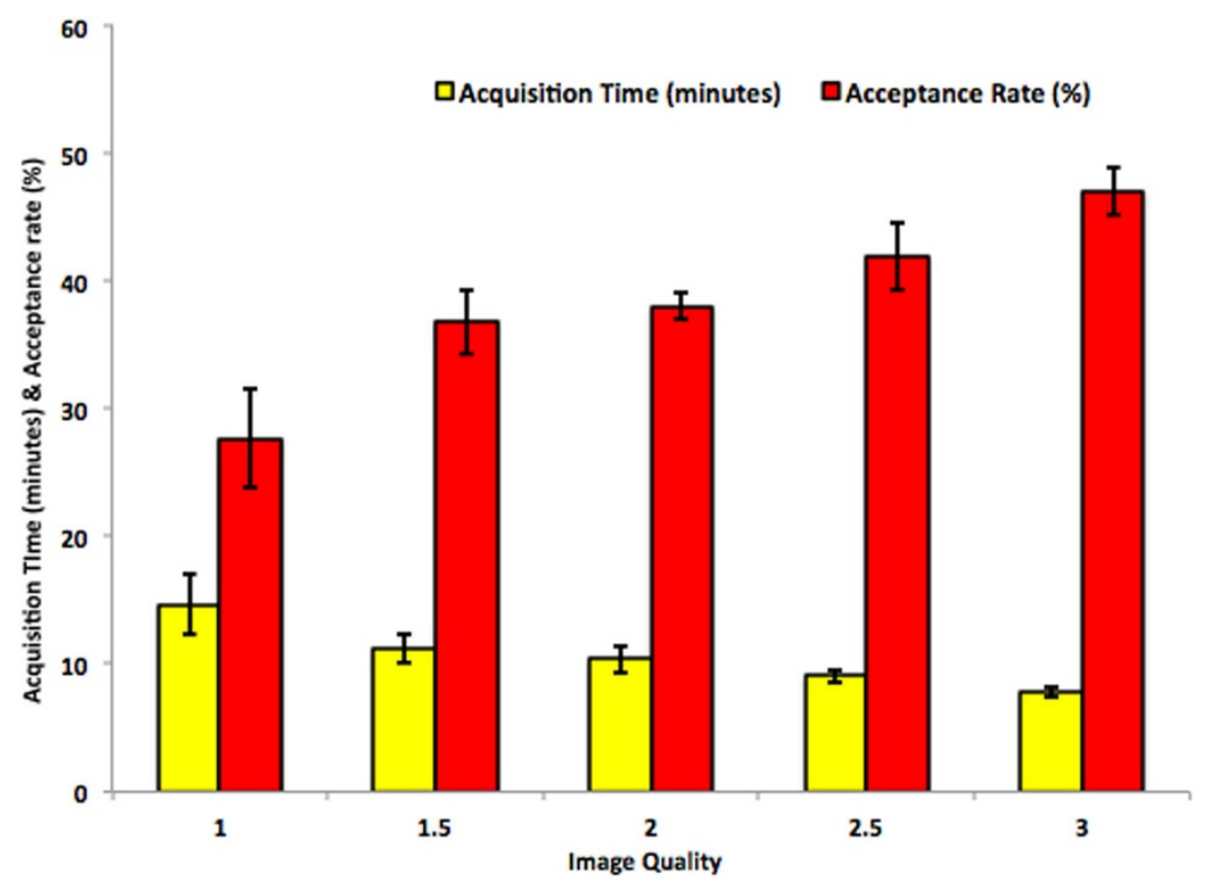

Figure 2 Dependence of image quality on the acquisition time and respiratory navigator acceptance rate.

\section{Author details}

'CARMA Center, Dept. of Cardiology, University of Utah, Salt Lake City, UT,

USA. ' $U C A I R$, Dept. of Radiology, University of Utah, Salt Lake City, UT, USA.

Published: 30 January 2013

doi:10.1186/1532-429X-15-S1-P269

Cite this article as: Vijayakumar et al:: Dependence of image quality of

LGE-MRI of the left atrium on the acceptance rate of respiratory

navigator and acquisition time. Journal of Cardiovascular Magnetic

Resonance 2013 15(Suppl 1):P269.
Submit your next manuscript to BioMed Central and take full advantage of:

- Convenient online submission

- Thorough peer review

- No space constraints or color figure charges

- Immediate publication on acceptance

- Inclusion in PubMed, CAS, Scopus and Google Scholar

- Research which is freely available for redistribution 